\title{
Bilateral Anterior Fracture-Dislocation of Shoulder Following Electrocution: About a Rare Case and Review of the Literature
}

\author{
Badreddine $\mathrm{D}^{1 *}$, Mohamed B ${ }^{1}$, Malika A², Adil L1, Reda 01, Mansour \\ $\mathrm{T}^{1}$ and Abdeloihab J1 \\ ${ }^{1}$ Department of Traumatology Orthopedics Surgery I, University of Rabat, Morocco \\ ${ }^{2}$ Department of medical imaging, University of Rabat, Morocco
}

\section{Case Report \\ Volume 3 Issue 1}

Received Date: February 07, 2019

Published Date: March 08, 2019

DOI: $10.23880 /$ jobd- 16000173

*Corresponding author: Dehayni Badreddine, Department of Traumatology Orthopedics I, Mohamed V Military Hospital, Faculty of medicine and pharmacy, Mohamed V University of Rabat, Morocco, Tel: +21266140895; Email: docteurdehayni@gmail.com

\begin{abstract}
Bilateral anterior dislocation of the shoulders associated with a bilateral fracture of the greater tuberosity is an extremely rare lesion. We reported a case of bilateral dislocation of the shoulder following an electrocution received and operated on in the Traumatology Orthopaedics I department of the Mohamed V Military Training Hospital in Rabat. The diagnosis was clinical as confirmed by radiological investigations; the patient received surgical treatment after failure of orthopaedic treatment, a bloody reduction in dislocation and osteosynthesis of the greater tuberosity of both shoulders. An evolution was marked by a satisfactory functional recovery of both shoulders. Even clinical examination can help to suspect dislocation, but x-rays are mandatory for an accurate and early diagnosis. Surgery is recommended for unreduced dislocations or displaced fractures; orthopaedic treatment is indicated in non-displaced fractures subsequent functional rehabilitation allows results after surgical and non-surgical treatment.
\end{abstract}

Keywords: Bilateral Anterior Dislocation of the Shoulder; Fracture of the Greater Tuberosity; Electrocution; Surgical Treatment

\section{Introduction}

Bilateral anterior dislocation of the shoulders associated with a bilateral fracture of the greater tuberosity is an extremely rare lesion. We report a case of bilateral anterior dislocation of the shoulder following an electrocution received and operated on in the Traumatology- Orthopaedics I department of the Mohamed V Military Training Hospital in Rabat.

\section{Case Presentation}

This is a 35-year-old patient, with no particular history, was admitted to the emergency department for a closed trauma of both shoulders with severe pain and total functional impotence following electrocution. He is a soldier who was the victim of an electric shock with a backward projection and a landing on both hands elbows in extension. The examination found bilateral bruises with signs of anterior dislocation of the shoulder, namely 


\section{Journal of Orthopedics \& Bone Disorders}

a sign of the shoulder, an external axe-blunt deformity and erasure of the delto-pectoral furrows, pain on palpation of the shoulder stump (Figure 1). Sensitivity and motor skills in the territory of the axillary nerves were maintained and the bilateral radial pulse was present for both limbs. Shoulder x-rays supplemented by a 3D reconstruction CT scan confirmed the diagnosis of bilateral shoulder dislocation in its anterior subcoracoidal variety with bilateral displaced the greater tuberosity fracture (Figure 2). An attempt to reduce sedation dislocations was unsuccessful. The patient was operated on in a semi-seated position, under general anesthesia, an acromial shoulder approach for both shoulders, a reduction in dislocations was achieved, with a reduction the greater tuberosity and its fixation by two washer screws, the shoulders were immobilized in adduction and internal rotation by elbow slings to the body for 04 weeks followed by functional shoulder rehabilitation.
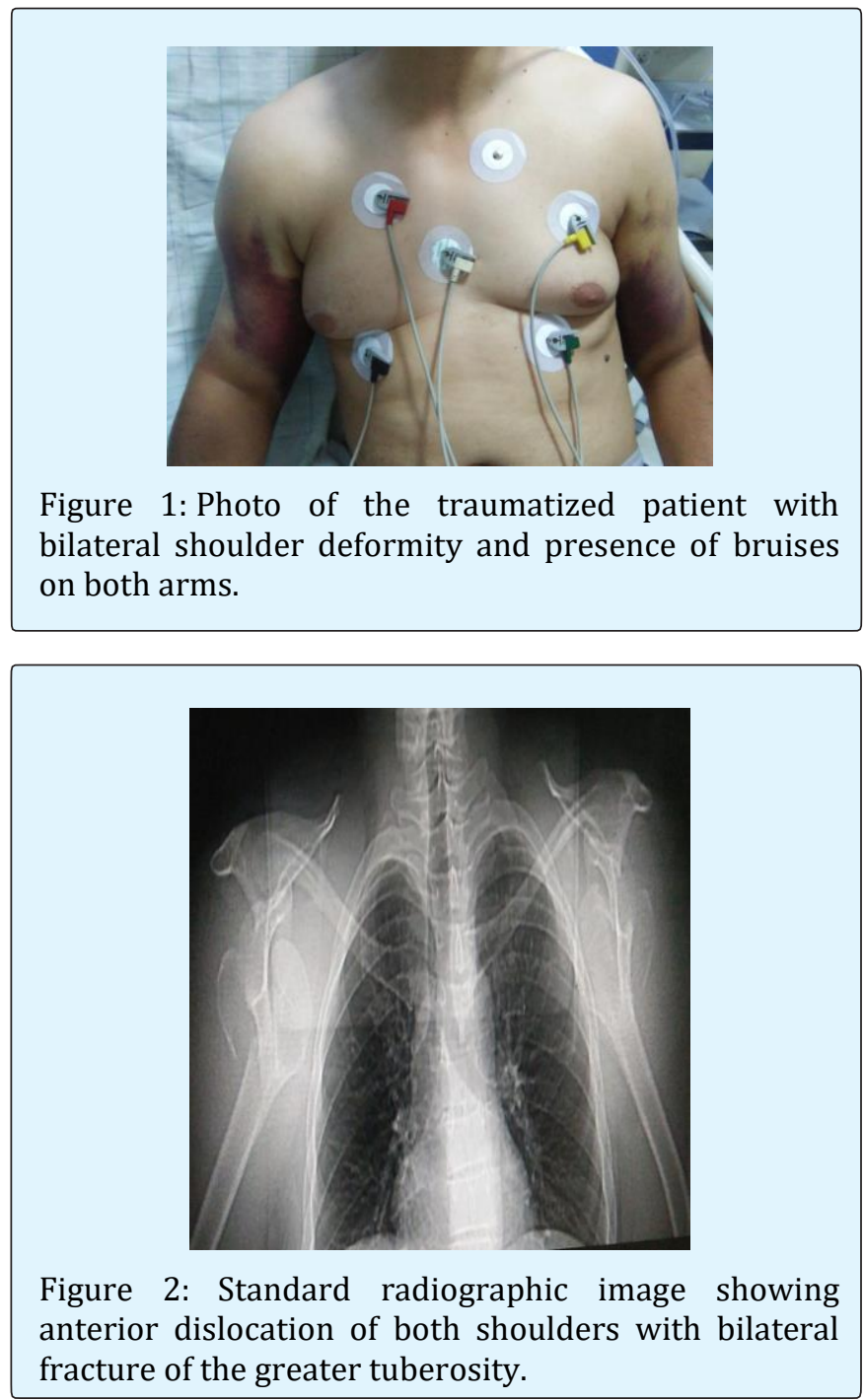

Badreddine D, et al. Bilateral Anterior Fracture-Dislocation of Shoulder Following Electrocution: About a Rare Case and Review of the Literature. J Ortho Bone Disord 2019, 3(1): 000173.

\section{Results}

The control radiograph at 08 weeks allowed noting the consolidation of the fracture of the two greater tuberosity (Figure 3). The articular amplitudes of the two shoulders were $120^{\circ}$ in abduction on the right and $130^{\circ}$ on the left, $40^{\circ}$ in external rotation on the right and $35^{\circ}$ on the left and the internal rotation reached D4 bilaterally (Figure 4). The patient returned to work after a 12-week break. There was no recurrence or instability of the shoulder after an 18-month retreat.
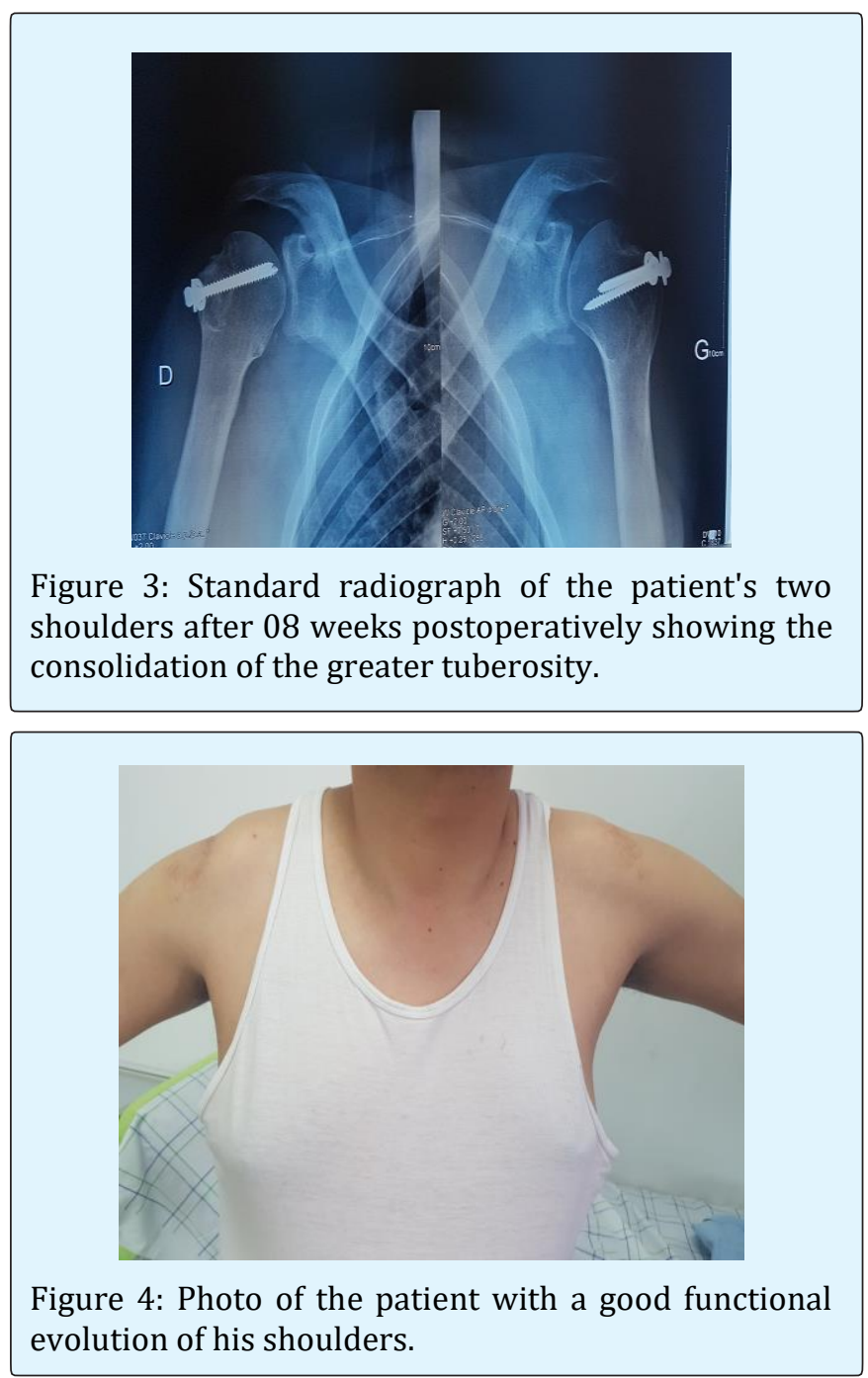

\section{Discussion}

Bilateral dislocation of the shoulders was first described in 1902 following excessive muscle contractions caused by camphor overdose [1]. They have 


\section{Journal of Orthopedics \& Bone Disorders}

been the subject of few publications [2,3]. Brown in 1984 identified three different etiologies out of a series of 90 cases of bilateral dislocations: violent muscle contractions (49\%), direct trauma $(23 \%)$ and absence of any trauma (36\%) [4]. These dislocations may be posterior; most frequent variety [5,6]. Brackstone described three etiologies as "triple E syndrome" (epilepsy or any convulsive seizure, electrocution and extreme trauma) [7]. Anterior dislocation of the bilateral shoulder is very rare, about 30 cases reported in the literature, dislocations associated with Fractures of the greater tuberosity represent $15 \%$ of cases Most were due to violent trauma caused by sports injuries and electrocution but also convulsions, in our observation; the patient was electrocuted with a backward projection and reception on both hands elbows in extension. Symptomatology is made of bilateral shoulder pain, with functional impotence of the upper limbs. Diagnostic confirmation requires standard $\mathrm{x}$-rays of the shoulder face and profile, supplemented by a CT scan to accurately assess the displacement of the large tuberosity and the number of bone fragments [8].

Treatment options for proximal humerus fracture dislocations in such cases require individualized approach for each side as per the personality of the fracture. Treatment options for proximal humeral fractures include both surgical and non-operative methods, but orthopedic treatment of complex fractures, in three or four parts, can lead to pseudarthrosis and shoulder stiffness [9]. The greater tuberosity is displaced in the approximately $15 \%$ of all anterior dislocations [10]. When a two part fracture dislocation is associated with a greater tuberosity fracture that is displaced, the diagnosis of rotator cuff tear is almost certain, and this can cause long term instability and functional impairment if the greater tuberosity fragment is not anatomically reduced $[10,11]$. Therefore we selected surgical fixation for this patient.

\section{Conflicts of Interest}

The authors do not declare any conflicts of interest.

\section{References}

1. Myenter H (1902) Subacromial dislocation from muscular spasm. Ann Surg 36(1): 117-119.
2. Dunlop CC (2002) Bilateral anterior shoulder dislocation: a case report and review of the literature. Acta Orthop Belg 68(2): 168-170.

3. Devalia KL, Peter VK (2005) Bilateral post-traumatic anterior shoulder dislocation. J Postgrad Med 51(1): 72-73.

4. Brown RJ (1984) Bilateral dislocation of the shoulders. Injury 15(4): 267-273.

5. Bouras Y, Elandaloussi Y, Nadil MA (2009) Bilateral anterior dislocation of the shoulders in the bodybuilder (about a case). Journal of Traumatology of Sport 26(4): 247-249.

6. Ryan J, Whitten M (1997) Bilateral locked posterior shoulder dislocation in a footballer. Br J Sports Med 31(1): 74-75.

7. Brackstone M, Patterson SD, Kertesz A (2001) Triple "E" syndrom: bilateral locked posterior fracturedislocation of the shoulders. Neurology 56(10): 14031404.

8. Dlimi F, Mahfoud M, Lahlou A, El Bardouni A, Berrada MS, et al. (2012) Bilateral anterior shoulder dislocation with bilateral fractures of the greater tuberosity: A case report. J Clin Orthop Trauma 3(2): 122-125.

9. Petty K, Price J, Kharasch M, Novack J (2014) Bilateral Luxatio Erecta: a Case Report. J Emerg med 46(2): 176-179.

10. Robinson CM, Khan LAK, Akhtar MA (2006) Treatment of anterior fracture dislocations of the proximal humerus by open reduction and internal fixation. J Bone Joint Surg Br 88(4): 502-508.

11. Ferkel RD, Hedley AK, Eckardt JJ (1984) Anterior fracture-dislocations of the shoulder: pitfalls in treatment. J Trauma 24(4): 363-367. 